\title{
ERRATUM
}

\section{List of reviewers for the Focused Issue}

Rosalie L Tung

Correction to: Journal of International Business Studies (2007) 38, 578. doi: 10.1057/Palgrave.jibs.8400276

In the above list of reviewers for the 'International Expansion of Emerging Market Businesses' Focused Issue, one reviewer, Daniel Van Den Bulcke, was inadvertently omitted. The guest editors, Rosalie L Tung and Yadong Luo, apologise to Professor Van Den Bulcke for this oversight, and thank him for his valuable work reviewing manuscripts for this issue of JIBS. 